\title{
FORCED AND CHILD MARRIAGE AT THE INTERSECTION OF HEALTH, GENDER AND HUMAN RIGHTS: UNDERSTANDING THE DETERMINANTS IN MOROCCO AND THE IMPACT OF THE MIGRATORY CONTEXT IN BELGIUM ${ }^{1}$
}

\begin{abstract}
Alexia Sabbe
Faculty of Medicine and Health Sciences, Ghent University, Belgium

With over 650 million women alive today already suffering the consequences of child marriage, the practice of forced and child marriage disproportionally affects girls and women. Given its impact on physical and psychological wellbeing, it is a serious form of violence against women.

In view of the global magnitude of forced and child marriage, and the increasing numbers of international migrants, the general objective of this research is to ascertain the determinants of forced and child marriage in Morocco and the impact of the migratory context on the issue among Moroccan migrants in Belgium.

Our research analysed forced and child marriage in both settings from two angles. First, we studied policies and the socio-cultural context in a top-down perspective through the analysis of legislation, public debates and through expert/stakeholder interviews. Secondly, we investigated the determinants of forced and child marriage in both research settings from a bottom-up perspective through Focus Group Discussions and household interviews, as well as investigating the impact of legislative conditions and restrictions on migrants and their families.
\end{abstract}

KEY WORDS: CHILD AND FORCED MARRIAGE, WOMEN'S RIGHTS, SEXUAL AND REPRODUCTIVE HEALTH, VIOLENCE, MOROCCO, MIGRATION, BELGIUM

\section{Introduction}

In global terms over 650 million women are currently suffering from the consequences of child marriage, a dramatic indication that the practice of forced and child marriage disproportionally impacts girls and women. Not only does it violate their fundamental human rights to bodily and sexual integrity, it is a public health problem on a global scale, effectively preventing women around the world from achieving their full potential. Given its impact on physical and psychological wellbeing, child and forced marriage, as a serious form of violence against women, has long-term detrimental effects on individu- 
als, families and communities as a whole. It brings about a wide range of specific health consequences. A growing body of research points to the huge economic costs of child and forced marriage, including direct costs to health care, law enforcement, etc. Given that the detrimental repercussions are inter-generational, full implementation of human rights and access to appropriate health care for women and girls is a prerequisite for global progress and sustainable well-being for all.

In Morocco, the changes to the social and legal framework surrounding sexual and reproductive rights since 2004 seemed very promising in terms of targetting violence against women in particular. Yet rates of child marriage and violence against women in general remain high, and appear to be on the rise.

Furthermore, as globalisation has increased levels of mobility and the numbers of migrants in host societies, the issue of child and forced marriage has become a concern on an international scale. In Europe, the issue is most often discussed within the contexts of immigration and integration on the one hand, and domestic violence on the other. Migration also includes marriage migration of second and subsequent generations bringing partners from their homeland into the host country. Spurred on by policies at the European Union level, Member States have been implementing laws and action plans to tackle the practice. As a result, minority groups have been specifically targeted by a combination of stringent criminal and immigration regulations. It is therefore important to understand the impact of this legal framework onmigrants in Europe, for whom the policies were designed. As one of the largest minority groups in Belgium, the Moroccan community is directly affected.

\section{Objectives and methods}

Given the global magnitude of forced and child marriage, and the increasing numbers of international migrants, the general objective of our research is to ascertain the determinants of forced and child marriage in Morocco and the impact of the migratory context on the issue among Moroccan migrants in Belgium. To this end, specific objectives were put forward. First we analysed the prevailing policies and laws regarding forced and child marriage in Europe and Belgium, including the risk factors and challenges in addressing the issue in Belgium. We also attempted to identify the overall impact of the (institutional) context and social environment on the practice among minority communities. Second, we aimed to understand the (institutional) context, social environment and cultural perceptions regarding forced and child marriage in Morocco. Third, we sought to ascertain the determinants of forced and child marriage at the community level in Morocco, and among the Moroccan communities in Belgium, including the impact of the migratory context. And fourth, our aim was to provide recommendations for the prevention and efficient targeting of forced and child marriage in Morocco and in Belgium. By providing stakeholders and policy makers with pertinent contextual knowledge and insights into constraints on the decision-making power of women, we aim to contribute to the prevention of forced and child marriage, and enhance the sexual and reproductive rights of women and girls. 
This study was conducted using a predominantly qualitative approach comprising the Multiple Streams Approach and participatory research. Kingdon's Multiple Streams Framework ${ }^{2}$ is applied to shed light on the policy process regarding forced marriage in Europe and its outcome. Furthermore, obtaining a genuine understanding of the contexts, and elements within each context, that are influencing child and forced marriage can only be achieved through a participatory approach with the involved parties. In this sense Focus Group Discussions (FGDs), stakeholder interviews and household interviews are central to the research. The Intergenerational Dialogue method was applied in FGDs in Morocco and Belgium. Additionally, Intercultural Dialogue was conducted in Belgium. Data collected from FGDs was useful in triangulating and validating the information from the household interviews and stakeholder interviews. A total of I6 FGDs were held in the research settings - 7 (Morocco) and 9 (Belgium). In order for the data to be as representative as possible, the locations of the FGDs incorporated rural/provincial and urban settings in accordance with the country in which they took place. In each country/research setting, approximately 20 households were targeted for in-depth semistructured interviews. An total of 125 women in Morocco and Io6 woman in Belgium participated in the FGDs and household interviews. Finally, interviews were held with 22 stakeholders in Morocco and 25 stakeholders in Belgium with first-hand experience of child and forced marriage.

The systematic framework developed by Hooghiemstra ${ }^{3}$ was applied. This model frames structural macro-level factors in the wider societal and demographic context. It also encompasses the role of social networks and community (meso-level) in the more immediate environment and micro-level facets such as personal characteristics (including beliefs and preferences). It also attends to direct family to help explain decisive factors in partner choice and marriage formation, thus uncovering any form of pressure or duress in this complex process. In addition, the correlation between the multi-level factors was taken into consideration.

We then applied thematic qualitative analysis, in which patterns or themes within the data were reported and analysed using framework grids. Raw data was sorted by theme and placed in the relevant part of the theoretical model through which a conceptual framework of themes and sub-themes was developed, allowing significant factors to emerge.

\section{Results}

Despite the 2004 reform of the Moroccan Moudawana (Family Code), which establishes a minimum age for marriage, child and forced marriage remains common. Under the law a judge can authorize marriage before the age of $\mathrm{I} 8$, a provision that is effectively used to a great extent.

From the viewpoint of professionals who are closely involved in tackling the issue in Morocco, policy measures and the law do have considerable potential in bringing child mar-

\footnotetext{
$2 \quad$ Kingdom, 1984

3 Hooghiemstra, 2001
} 
riages and forced marriages to a halt. Yet despite reforms, equality gaps between men and women remain in a number of laws, particularly in relation to family matters, which continue to weaken women's agency. Women are still not sufficiently protected from violence. The problem lies in the fact that the applicable legal frameworks are interpreted through the lens of restrictive social norms, thus further reinforcing the bias towards women. Social norms in Morocco impact all aspects of agency, including economic participation, roles in family life and the ability to participate in public life. They are often maintained and strengthened through biased public sector institutions whose services fail to comply with applicable legal and administrative frameworks. This is the case, for example, when judges in family courts use a legal loophole to apply their own viewpoints and beliefs to authorize underage marriages.

The combination of unequal treatment in legislation together with limiting social norms that affect women's behaviour create severe obstacles to women's agency. Legal restrictions reflect the prevailing social norms, especially with regard to family and personal life, where the concept of family honour is effectively upheld by the law. This is evident in the criminalization of consensual sexual relations outside of marriage, yet marital rape is not punished. Norms are enforced through family and community pressure on the one hand, and through self-enforcement by the individual on the other hand. Shame is an inherent part of the culture. This is also discernible in the Moroccan Belgian community, where shame is strongly associated with premarital relationships.

The importance of specifically directing efforts towards the older generation of parents and grandparents emerged from the research. As a result of the use of the Intergenerational Dialogue method, participants repeatedly emphasized the need for more opportunities to have open communication between parents and children. The pressure on young women and girls from the elders is often considerable, effectively discouraging daughters from claiming their right to freely enter into marriage. Women in Morocco who openly oppose the will of their fathers are subject to intimidation and ostracism from their families, effectively isolating them in a male dominated public space.

This also highlights the problem with the specific criminal law against forced marriage in Belgium and other European countries. It takes away the victim's agency, in the sense that police-led interventions and public prosecutors take over without consent from the women or girl herself. Women's agency within minorities is effectively ignored, and victims find themselves alone, unable to remain in their family and social environment. Supporting women from within their communities is overlooked in favour of governments' top-down focus on regulation. Similarly, linking immigration policy with the issue of forced marriage redirects remedial measures away from victims and legitimates the use of state power to punish and restrict. The prevailing policy discourse fails to engage with this dynamic and is at odds with the needs of those it seeks to assist.

The question of whether or not a specific criminal law and tighter immigration controls are effective means of combatting forced marriage may be a moot point - at least in the viewpoint of (potential) victims. Law and policy treat marriage as a matter pertaining to public interest and not purely as a private matter. Its impact on society and on the lives of those involved legitimizes this interest, yet little or no regard is given to the health effects 
on victims of forced marriage and those at risk. As attention is placed on criminalization and stringent immigration policies, ethnic minority population groups bear the greatest burden. The conceptualisation and portrayal of forced marriage as a cultural issue acts as a barrier to appropriate intervention. Not only do they suffer reduced access to health providers, the potentially adverse effects of the current policy framework affects their health and well-being at large. The serious consequences for women, including sexual violence, and the physical and psychological health risks associated with it, receive little attention. The research also highlighted that (potential) victims feel they are not able to access mainstream service providers for fear they will not be understood. Participants from the Moroccan Belgian community feel more comfortable accepting the help of someone with the same Moroccan background, without which they are unlikely to enlist the help of an aid organisation or social services.

Among the Moroccan Belgian community, forced and child marriage is no longer an acute problem. This does not mean there are no difficulties to overcome. Considerable challenges lie in the "double standards" that apply to men and women in the community. The disempowerment of women as a result, only leads to increased vulnerability and violence in some cases, highlighting the need for tailored support by social services and in health centres.

The migratory context did not appear to perpetuate or give rise to the occurrence of forced marriages and child marriages in a significant way. The results, however, tentatively point to a strengthening of the element of religion. It not only surfaces as the most imperative element in partner choice, its re-educating role as a deterrent for forced marriage is also notable.

\section{Conclusions and recommendations}

The legal framework in Morocco fails to acknowledge the underlying fundamental concepts of women's and girls' rights. Instead, women and girls are often conflated with their stereotyped gender roles as wives and mothers, particularly with regard to violence. This bias is reflected in the inadequate level of protection afforded to women and girls who fall outside stereotyped gender roles. A holistic approach to violence against women and girls is necessary, recognizing that gender is socially constructed. Among the recommendations, the decriminalization of sexual relations outside marriage is emphasized and the minimum marriage age of $\mathrm{I} 8$ should be adhered to, allowing no exceptions.

Pressure from older generations was reported to be a significant determinant of child and forced marriage. In Moroccan society in general, the desires, character and talents of the individual are often overlooked in favour of what is beneficial for the collective: family and community. Therefore, personal characteristics at the micro-level overall have less of an impact. Working directly on education, and above all fostering self-confidence and agency in girls and women, can in the long term, increase the impact that micro-level factors will have on preventing forced marriage. This should go hand in hand with sensitization efforts geared towards the older - often illiterate - population groups, using television and radio, which is crucial to tackling forced and child marriage. The results redefine the role of women's associations, social workers and so on, with the recom- 
mendation that their efforts are focussed on raising awareness among older generations. Child and forced marriage are an outcome of social norms and community pressure. Financial poverty certainly adds to the pressure, making the short-term relief of the burden of poverty by marrying off daughters a viable course of action. Yet, only relieving financial pressure, through financial incentives for example, is insufficient to achieve the Sustainable Development Goal (SDG) of ending child and forced marriage by 2030. This is demonstrated by the paradoxical experience in the Marrakech region, where the prevalence of child marriage increased despite high rates of economic growth and decline in poverty in the region. Interventions that fail to address the underlying social norms have limited effects. In light of these findings, a long-term and holistic view is necessary. Dimensions such as realized rights (gender equality in norms and laws), health, and access to education should be the focal point to enhance women's and girls' agency on all levels (micro-, meso- and macro-level). Rather than cost-benefit based approaches that rely on single-focus indicators, a multi-dimensional approach provides the highest likelihood of improving overall health and well-being in the long run.

In order to successfully address child and forced marriage, programs and interventions are required that are tailored to the local context. Efforts to increase school attendance and educational attainment in the Marrakech region should be supported with complementary efforts such as gender-conscious life-skills programs in schools and structured engagement with communities. Complementary efforts should also include addressing barriers to adequate higher educational and employment opportunities for girls, as well as ensuring their safety and security in public spaces.

Given that child and forced marriage is deeply rooted within patriarchal societies, the requirement that working with men and boys be included is paramount. Our research pointed to the need for the father's authority to remain intact in any intervention, demonstrating the necessity to engage fathers, fathers-in-law, brothers, etc. Most programs do not meaningfully address men and boys within households to share obligations and household responsibilities set forth in programmatic interventions. Therefore gender relations within families are not configured, which undermines the success of these interventions in the long run. Addressing the ingrained 'double standards' for men and women in the Moroccan Belgian community would also benefit from directing efforts towards men and boys to level the gender inequality.

A profound shift is paramount where religious and traditional arguments are deeply embedded in the social fabric of the community. Families and parents often look to cultural and religious norms to justify child and forced marriage. In the case of Morocco, religious leaders can be effective advocates of ending child marriage and forced marriage by endorsing the increase of the marriage age on the one hand, and by specifying that coercion to marry is not condoned by the Islam. Research in Belgium indicates that religion is already playing a re-educational role among the Moroccan Belgian community with regard to forced and child marriage.

Overall, in light of developments over the past decade, and the increased potential for terrorism, policy choices in Europe have been based on security concerns. Legislation such as criminalizing forced marriage has detrimental outcomes for the desired goal of pro- 
tecting women and children. Prevention of forced marriage cannot be used to limit free movement rights of third-country national family members of EU citizens beyond what is allowed by the Free Movement Directive (2004/38/EC). Approaching forced and child marriage as a human rights issue and a form of gender-based violence avoids stigmatization of ethnic minorities or communities that are linked to this type of practice. Moreover, it paves the way for effective solutions that are not essentially punitive or restrictive. Health services and programs are an appropriate entry point for addressing interpersonal violence against women and girls, such as forced and child marriage, rather than the emphasis on prosecution and criminalization. A coordinated response for (potential) victims of forced marriages within health facilities in Belgium supports wellbeing, health and safety while simultaneously honouring women's agency. Trained frontline health care workers, situated in local (community) health centres, offer the advantage of being easily accessible and providing anonymous care. Women who experience violence are more likely to use health services than those who do not, although they rarely explicitly disclose violence as the underlying reason. Health care providers are often the first point of professional contact for survivors/victims of violence, and yet the underlying violence is frequently invisible to them. In many cases, health services are currently inadequate due to the invisible nature of the violence itself. Reframing the discourse on forced marriage to one focusing on wellbeing and respecting women's agency, effectively embedding protection in a broader coordinated multi-sectoral policy is a challenge that policymakers should embrace. Providing training and tools for health workers and other frontline workers is paramount.

\section{References}

Kingdon, J.W. (I984). Agendas, alternatives and public policies. Boston and Toronto: Little, Brown and Company.

Hooghiemstra, E. (200I). Migrants, Partner Selection and Integration: Crossing Borders? Journal of comparative family studies, 32(4): 6oI-626. 